\title{
ANÁLISE SOCIOAMBIENTAL DA PRODUÇÃO DE GOIABA DO MUNICÍPIO DE CARIÚS (CE), BRASIL
}

\author{
SOCIO-ENVIRONMENTAL ANALYSIS OF GUAVA \\ PRODUCTION IN THE MUNICIPALITY OF CARIÚS (CE), \\ BRAZIL
}

\author{
Sostenes Gomes de Sousa ${ }^{1}$ \\ Girlaine Souza da Silva Alencar ${ }^{2}$ \\ Francisco Hugo Hermógenes de Alencar ${ }^{3}$ \\ Celme Torres Ferreira da Costa
}

http://dx.doi.org/10.15359/rgac.3-59.8

\section{RESUMO}

A "revolução verde", disseminada a partir da segunda metade do Século XX, difundiu o uso de agentes químicos e máquinas pesadas na agricultura. No Brasil, os agricultores tiveram que se adequar a esta nova política de massificação do uso de agrotóxicos e fertilizantes, devido à obrigatoriedade de aplicações sucessivas destes produtos nas culturas que tinham financiamento bancário. Estudos têm demostrado que a falta de informação por parte dos trabalhadores no uso e manuseio frequente destes venenos, causa graves problemas a sua saúde, contamina a biota e os

1 Graduando em Engenharia Ambiental (Instituto Federal do Ceará - IFCE/ Juazeiro do Norte). E-mail: sostenes-sousa@hotmail.com.

2 Professora Titular em Ciências Ambientais do Instituto Federal do Ceará. Av. Plácido Aderaldo Castelo, 1646 - Planalto, Juazeiro do Norte. E-mail: girlainealencar@gmail.com.

3 Professor Titular em Zootecnia do Instituto Federal do Ceará. Av. Plácido Aderaldo Castelo, 1646 - Planalto, Juazeiro do Norte. E-mail: hugohermogenes@gmail.com.

4 Doutora em Engenharia Civil (Universidade Federal do Ceará). Rua Tenente Raimundo Rocha, S/N - Bairro Cidade Universitária, Juazeiro do Norte-CE. E-mail: celme.torres@ufca.edu.br

Fecha de recepción: 23 de noviembre de 2016

Fecha de aceptación: 9 de mayo de 2017 
consumidores. Atualmente o estado do Ceará tem se destacado como um importante produtor de frutas. Neste contexto, o município de Cariús-CE, Brasil, se destaca com uma produção anual de $200 t$ de goiaba. Entretanto, há poucos estudos acerca dos impactos gerados por esta atividade. O objetivo deste estudo foi levantar os aspectos socioambientais da produção de goiaba do município de Cariús - CE, Brasil, com vistas a identificar os problemas socioambientais gerados.

Palavras-chave: Fruticultura; Trabalhadores; Agrotóxicos.

\begin{abstract}
The "green revolution", spread from the second half of the $20^{\text {th }}$ century, disseminated the use of chemical agents and heavy machinery in agriculture. In Brazil, farmers had to adapt to this new policy for the widespread use of pesticides and fertilizers, due to the mandatory subsequent applications of these products in crops with bank financing. Studies have shown that the lack of information on the part of the workers in the frequent use and handling of these poisons causes serious problems to their health, contaminates the biota, and consumers. Currently, the state of Ceará has stood out as an important fruit producer. In this context, the municipality of Cariús-CE, Brazil, stands out with an annual production of $200 \mathrm{t}$ of guava. However, there are few studies regarding the impacts generated by this activity. The purpose of this study was to assess the socioenvironmental aspects of guava production in the city of Cariús - CE, Brazil, in order to identify the socioenvironmental problems generated.
\end{abstract}

Keywords: Fruits; Workers; Pesticides.

\title{
Introdução
}

A partir de meados do Século XX a produção agrícola sofreu grandes transformações com o objetivo de aumentar a produção e a produtividade. Entretanto, esta "revolução" incluiu o uso intensivo de agrotóxicos, fertilizantes e maquinários no campo, causando muitos impactos ambientais como a contaminação do solo, da água e comprometendo a saúde dos trabalhadores.

Agrotóxicos são compostos tóxicos e altamente prejudiciais ao meio ambiente, utilizados para eliminar pragas e doenças das culturas. Entretanto, a utilização indiscriminada contamina o solo, o ar, águas subterrâneas e superficiais, causando sérios danos ao meio ambiente.

A contaminação do solo intensifica o processo de desertificação e a contaminação da água inviabiliza a produção e é especialmente preocupante no Semiárido brasileiro devido sua tendência natural à restrição hídrica.

$\mathrm{O}$ uso excessivo de água por grandes produtores agrícolas e industriais, aliado ao mau uso deste recurso pode acarretar a diminuição do volume disponível, além de causar a contaminação por esgoto, metais pesados, agrotóxicos e fertilizantes dos aquíferos superficiais e subterrâneos pela lixiviação. 
Dentre as formas de contaminação dos trabalhadores, há uma multiplicidade de processos através dos quais as populações humanas estão expostas aos produtos, desde as mais comuns como pela ingestão, via dérmica e inalatória até formas mais complexas como pelo ambiente ou pela biota. Em relação aos impactos à saúde dos trabalhadores, pode causar desde dor de cabeça, tontura, desmaio e convulsões até abortos espontâneos e má formações congênitas, dentre outros (OPAS/OMS, 1996; Boccolini, 2010).

O uso crescente de agrotóxicos no Brasil tem sido motivo de preocupação, pois desde 2008 o país é campeão mundial no consumo destes produtos. O Ceará tem se destacado nos últimos anos como um importante produtor de frutas, entretanto, há poucas pesquisas sobre os impactos dos agrotóxicos na saúde dos trabalhadores. Neste contexto, identifica-se a necessidade de estudos locais que envolvam o ambiente da fruticultura tendo como ponto chave a contaminação que está sendo causada pelo uso indevido de agroquímicos.

O destaque para o estado é a produção de goiaba que em 2013 alcançou a produção de 3.415 toneladas. O município de Cariús localizado na região Centro Sul do estado, tem uma produção de 200 t/ano. Entretanto, há poucos estudos sobre os impactos socioambientais causados por esta atividade (Adece, 2013).

Nesse contexto, identifica-se a necessidade de estudos locais para avaliar os problemas socioambientais na cultura da goiabeira no município de Cariús.

\section{O efeito do uso de agrotóxico sobre a saúde humana}

De acordo com Geremia (2011), os agrotóxicos foram criados pela indústria bélica e utilizado amplamente na Segunda Guerra Mundial para destruir as culturas do "inimigo" (grifo nosso), através de pulverizações aéreas. No âmbito nacional, a autora afirma que o governo "... incentivava o agricultor a comprar veneno, através de Crédito Rural, ao instituir a inclusão de uma cota definida de agrotóxicos para cada financiamento requerido".

Carson (2010) compara o uso de agrotóxicos a um “... constante gotejar da água que, pouco a pouco, desgasta a pedra mais dura, esse contato do nascimento até a morte com produtos químicos perigosos, pode no fim, revelar-se desastroso". A autora acrescenta as exposições recorrentes, 
mesmo que em quantidades pequenas, contribui para a acumulação progressiva de produtos químicos em nosso corpo e, assim, para o envenenamento cumulativo.

A despeito de não haver dados concretos sobre a contaminação dos trabalhadores por agrotóxicos no âmbito nacional, Araújo (2010) estima que de 150 a 200 mil trabalhadores rurais brasileiros sofrem intoxicação anualmente. Entretanto, enfatiza que os dados relativos a esta temática não reflete a realidade do país devido à insuficiência de informações.

Embora a pesquisa brasileira no que se refere ao impacto do uso de agrotóxicos na saúde humana também tenha crescido nos últimos anos, ainda é insuficiente para conhecer a extensão da carga química de exposição ocupacional e a dimensão dos danos à saúde, decorrentes do uso intensivo de agrotóxicos. Um dos problemas apontados é a falta de informações sobre o consumo de agrotóxicos e a insuficiência dos dados sobre intoxicações por estes produtos (Araújo, 2010, p. 10).

Peres et al., (2003) acrescentam que no meio rural brasileiro o uso inadequado dos agrotóxicos tem causado graves e complexos problemas à saúde dos trabalhadores, desde dor de cabeça e tontura até desmaios e convulsões. E que a contaminação se dá não somente por contato direto com os produtos, mas, também, por meio do contato com ambiente ou objetos contaminados e da contaminação da biota de áreas próximas às plantações agrícolas. Entretanto, ressaltam que os processos através dos quais as populações humanas estão expostas aos produtos, constituem-se verdadeiros mistérios, dada a multiplicidade de fatores que estão envolvidos, por este motivo, muitas vezes não atribuem o problema ao uso de agrotóxicos.

Outro problema decorrente ao uso de agrotóxicos são os resíduos deixados nos alimentos. De acordo com Pedroza (2013) estudo feito pelo Programa de Análise de Resíduos de Agrotóxicos em Alimentos (Para) realizado no ano de 2010 em amostras coletadas nas 26 Unidades Federais, demonstrou que um terço dos alimentos consumidos cotidianamente pelos brasileiros está contaminado por agrotóxicos. Sendo que $63 \%$ das amostras analisadas apresentaram contaminação por agrotóxicos e destas, $35 \%$ apresentaram ingredientes ativos não autorizados (NA) para aquele cultivo e/ou ultrapassou os limites máximos de resíduos (LMR). 
De acordo com a Anvisa (2010) os ingredientes encontrados (Indosulfan, Metamiclofós e Acefato) têm elevado grau de toxidade aguda comprovada e causam problemas neurológicos, reprodutivos, desregulação hormonal e até câncer. A despeito de serem proibidos em vários locais do mundo, como União Europeia e Estados Unidos, ainda são comercializados no Brasil.

Trabalhos realizados por Alencar $(2006 ; 2013)$ com floricultores do Cariri cearense, constatou que os principais problemas em relação aos agrotóxicos, é a falta de informações técnicas, uso inadequado ou não uso de equipamentos de proteção individual (EPI's) durante a aplicação dos produtos, dosagens inadequadas (acima ou a baixo da recomendada), uso de venenos não indicados para as culturas e descarte inadequado das embalagens vazias.

\section{Fruticultura no Brasil e Ceará}

A produção mundial de frutas é superior a 800 milhões de t/ano e o Brasil é o terceiro maior produtor. Em 2014 exportou frutas frescas para 58 países. A diversidade de bioclimas contribui para a ampla variedade de espécies produzidas, o incremento da produtividade, as formas de apresentação e de industrialização colocam as frutas em destaque no agronegócio brasileiro (Reetz et al., 2015).

A produção de frutas no Ceará em 2010 foi de 1.061 .305 toneladas, representando R \$752,4 milhões. Esse bom desempenho faz com que o estado seja o maior exportador de frutas da região Nordeste (Ipece, 2010). Segundo a Agência de Desenvolvimento do Ceará (Adece), o Ceará produziu 20 milhões e 49 mil toneladas de frutas, representando 5,2\% da produção no país, destacando-se como o $1^{\circ}$ lugar na produção de caju, $2^{\circ}$ maior produtor de coco, maracujá e melão e o $3^{\circ}$ na produção de mamão.

No que se refere às frutas regionais, o estado se destacou no mercado com a produção em larga escala de cajá, cajarana, jaca, ata, graviola, banana, entre outros. Ainda em 2013, o Ceará exportou 146,2 mil toneladas de outros produtos de fruticultura, representando $21,3 \%$ do total nacional e o ocupou o $3^{\circ}$ lugar em exportações de frutas, garantindo US\$ 108,1 milhão.

Como destaque na fruticultura dentre todos estados brasileiros o Ceará teve um aumento significativo da comercialização de goiaba, que alcançou 3.415 toneladas com um lucro total de $\mathrm{R} \$ 3.262 .400$ só no ano 
de 2013. O município de Cariús, localizado na região Centro Sul, é o $4^{\circ}$ produtor de goiaba do estado, produzindo 200 t/ano (Adece, 2013).

\section{Evolução da cultura da goiaba no brasil e no Ceará, Brasil}

A goiaba (Pisidium guajava $L$ ) é uma fruta tropical originária das Américas Central e do Sul, porém é altamente adaptável a vários tipos de clima (Freitas, 2010). Atualmente, pode ser encontrada em diversas regiões do Brasil. Sua produção teve início na década de 1970, quando grandes áreas com pequenos polos industriais foram implantadas no território brasileiro (Choudhury et al, 2001), com isso a produção sofreu grandes modificações de mercado, com o surgimento de produtos industrializados na forma de sucos e doces.

De acordo com o Serviço Brasileiro de Apoio às Micro e Pequenas Empresas - SEBRAE (2016) os principais problemas enfrentados pelos produtores de goiaba são decorrentes de pragas como as moscas da goiaba (Anastrepha fraterculus, Anastrepha obliqua e Ceratitis capitata), o psilídeo (Trizoida sp.) e o gorgulho (Cosnotrachelus psiddi). As culturas também podem ser afetadas por doenças causadas por fungos como a ferrugem (Puccina psiddi), verrugose (Elsione pitangae) e antracnose (Sphcelona psidi).

As técnicas de ensacamento dos frutos e uso de agrotóxicos foram utilizadas pelos agricultores para o controle destas pragas e doenças, com isso a cultura da goiaba se expandiu rapidamente em todo o território brasileiro. Nos anos de 2009 a 2014 a produção de goiaba teve um aumento de $20,8 \%$ gerando um lucro acumulado de $\mathrm{R} \$ 1.504 .719$ reais. Neste período, a região Nordeste teve um aumento de produção de $11,5 \%$ e o estado do Ceará destacou-se como o maior produtor, com um aumento de produção de 17,75, conforme é demonstrado na Figura 1. 
Figura 1: Evolução da produção de goiaba no Brasil, Nordeste e Ceará

$$
(2009-2014)
$$



Fonte: IBGE, 2016.

Organização: Sousa, 2016.

Em contrapartida, a área plantada em hectares no estado do Ceará sofreu um acréscimo de 98,3\% no decorrer desses seis anos, evidenciando que os produtores da região estão buscando elevar as suas produções de goiaba (Figura 2).

Figura 2: Evolução da produção de goiaba em relação a área planta no Ceará $(2009-2014)$

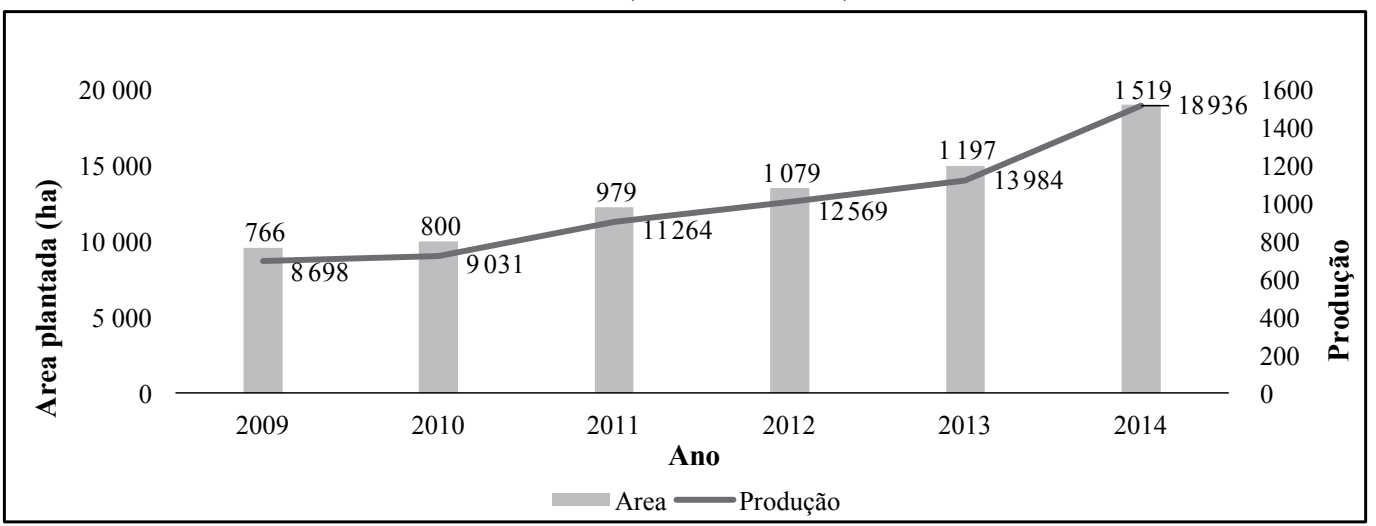

Fonte: IBGE (2016).

Organização: Sousa, 2016. 


\section{Caracterização da área de estudo}

O semiárido brasileiro engloba 1.133 municípios, ocupando uma área de $982.563,3 \mathrm{~km}^{2}$ e uma população de aproximadamente 47 milhões de habitantes. Cerca de $89,5 \%$ concentra-se na região Nordeste (Ibge, 2015). As regiões semiáridas têm um significativo déficit hídrico, apresentando médias pluviométricas anuais iguais ou inferiores a $800 \mathrm{~mm}$ e índice de insolação média de 2.800 h/ano (Funceme, 2015).

Segundo Aldo (1997) o Semiárido brasileiro tem algumas características como:

"[...] ter quase oito meses de ausência de chuvas que ocorrem anualmente, secas periódicas e cheias frequentes dos rios intermitentes, solos arenosos, rasos, salinos e pobres em nutrientes essenciais ao desenvolvimento das plantas. A vegetação básica do Sertão é a caatinga, que apresenta grande variedade de formações, todas adaptadas à prolongada estação seca" (p.9).

Nas regiões semiáridas a chuva ainda representa a única fonte de realimentação dos cursos dos rios e dos aquíferos, principalmente os localizados na região Nordeste. Além da grande perda de água causada devido os solos serem em sua maioria rasos e arenosos, há também um grande fluxo de evaporação da agia ocasionada pelas elevadas temperaturas da região (Albeiro et al, 2015).

Visando a diminuição desses problemas naturais a população do Semiárido, começou em 1890 por meio dos órgãos governamentais, a construir açudes públicos, barragens, barreiros, reservatórios de pequeno porte e poços a fim de armazenar a água que seria utilizada posteriormente para o abastecimento das populações, rebanhos e plantio (Assunção, Livingstone, 1993).

A região em estudo localiza-se no Semiárido nordestino, centro sul do estado do Ceará no município de Cariús (Figura 3). Compreende os distritos de Bela Vista, Caipu, São Bartolomeu e São Sebastião. Está região está localizada na bacia do Alto Jaguaribe e abrange uma área total de $1061,73 \mathrm{~km}^{2}$ a uma altitude de 240,6 metros, com uma população estimada em 18.567 habitantes (Ipece, 2015). O município apresenta um Índice de Desenvolvimento Humano (IDH) de 0,597 e um PIB per capita de 3.787,19 reais (Ibge, 2010). 
Figura 3: Localização do município de Cariús/CE

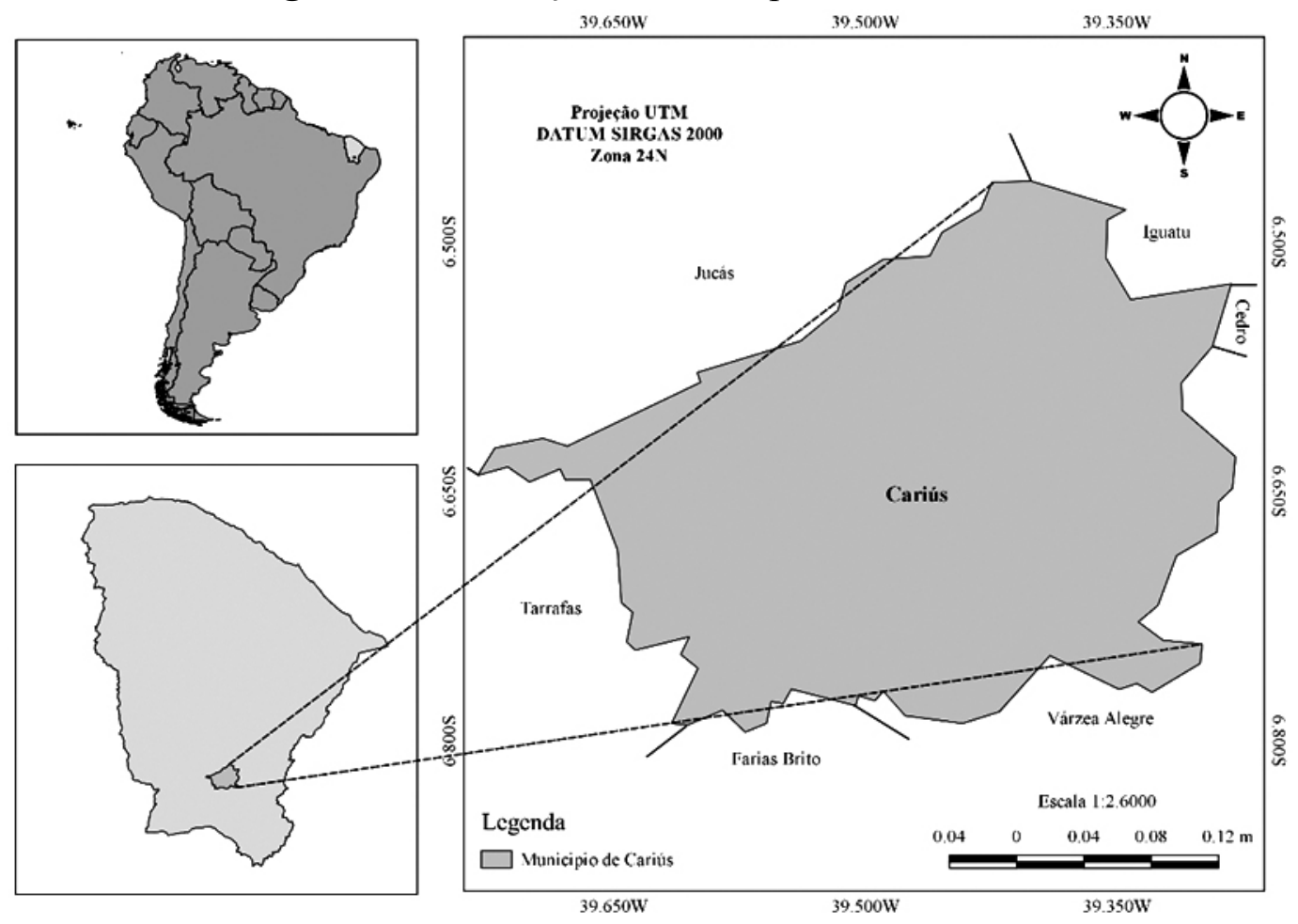

Fonte: IBGE, 2016.

Organização: Sousa, 2016.

Em relação ao relevo, a área em estudo apresenta uma feição de Depressões Sertanejas e Maciços Residuais. O solo bem definido e bastante diversificado, com predominância de Neossolos, Luvissolos e Nitossolos. Os três tipos de solo apresentam uma boa fertilidade natural e permeabilidade (Quadro 1), entretanto estas características podem variar de acordo com as localidades e interferências antrópicas (Embrapa (2006); Alencar (2013); Ipece (2015)). 
Quadro 1 - Descrição dos tipos de solos que ocorrem no município de Cariús/CE

\begin{tabular}{|c|l|l|l|}
\hline IPECE & $\begin{array}{l}\text { Solos Aluviais e } \\
\text { Solos Litólicos }\end{array}$ & $\begin{array}{l}\text { Podzolico Vermelho }- \\
\text { Amarelo }\end{array}$ & $\begin{array}{l}\text { Terra Roxa Estrutura } \\
\text { Similar }\end{array}$ \\
\hline EMBRAPA & Neossolos & Luvissolos & Nitossolos \\
\hline Características & $\begin{array}{l}\text { Constituídos por } \\
\text { material mineral ou } \\
\text { por material orgânico } \\
\text { pouco espeço. Com } \\
\text { predominância } \\
\text { de solos poucos } \\
\text { evoluídos. }\end{array}$ & $\begin{array}{l}\text { Solos minerais não } \\
\text { hidromórficos, com } \\
\text { alto gradiente textural } \\
\text { e de atividade de } \\
\text { argila. }\end{array}$ & $\begin{array}{l}\text { Apresentam baixa } \\
\text { atividade de argila } \\
\text { e apresentarem boa } \\
\text { drenagem. }\end{array}$ \\
\hline Profundidade & $\begin{array}{l}\text { Pouco a muito } \\
\text { profundos. }\end{array}$ & $\begin{array}{l}\text { Pouco profundos (60 } \\
\text { a 120 cm). }\end{array}$ & $\begin{array}{l}\text { Profundos. } \\
\text { Fertilidade }\end{array}$ \\
$\begin{array}{l}\text { Maior fertilidade } \\
\text { planas e menor em } \\
\text { áreas de planícies. }\end{array}$ & $\begin{array}{l}\text { Alta fertilidade } \\
\text { natural. }\end{array}$ & $\begin{array}{l}\text { Alta a baixa } \\
\text { fertilidade natural. }\end{array}$ \\
\hline $\begin{array}{l}\text { Limitações } \\
\text { para o uso } \\
\text { agrícola }\end{array}$ & $\begin{array}{l}\text { permesentar pouca } \\
\text { zonas distróficas } \\
\text { necessitam de } \\
\text { calagem para } \\
\text { correção da acidez. }\end{array}$ & $\begin{array}{l}\text { Em relevos declivosos } \\
\text { mecessário }\end{array}$ & $\begin{array}{l}\text { Em relevos } \\
\text { acidentados o solo } \\
\text { tem suscetibilidade a } \\
\text { erosão. }\end{array}$ \\
\hline
\end{tabular}

Fonte: EMBRAPA (2006); Alencar (2013); IPECE (2015); Santos e Zaroni (2015).

Organização: Sousa, 2016.

O tipo de clima predominante é o Tropical Quente Semiárido com temperaturas anuais variando entre $26^{\circ}$ a $28^{\circ}$ e pluviosidade anuais que podem chegar a $856,6 \mathrm{~mm}$ (Funceme, Ipece, 2015). O período chuvoso estende-se entre os meses janeiro a abril e o período seco de maio a dezembro. Porém as chuvas são irregulares em curto espaço de tempo (Figura 4). 
Figura 4: Médias mensais das precipitações do município de Cariús/CE $(1979-2014)$

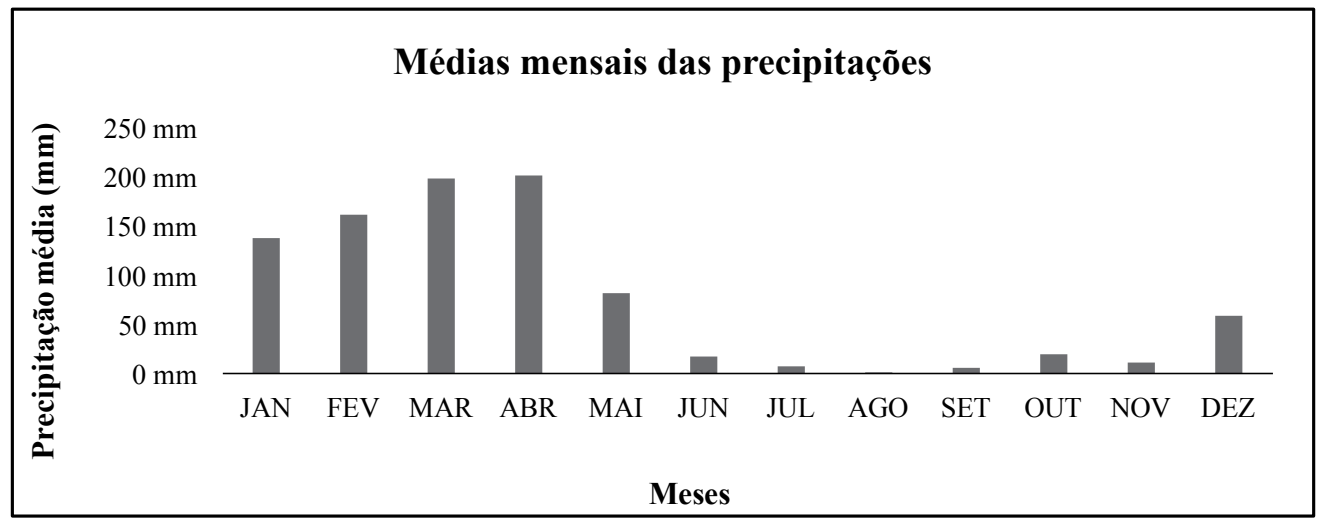

Fonte: FUNCEME, 2014.

Organização: Sousa, 2016.

Pelo exposto, a região apresenta limitações e características das regiões Semiáridas como alta evaporação potencial, déficit hídrico significativo e baixa precipitação pluvial (Molion; Bernardo, 2012).

Entretanto, possui diversas características que favorecem a prática da fruticultura como abundância de água subterrânea, boa fertilidade natural, temperaturas médias constantes, que favorecem o bom desenvolvimento das plantas e frutos, além de contar com reservatórios e açudes como o do Muquém (Figura 5). 
Sostenes Gomes de Sousa, Girlaine Souza da Silva Alencar,

Francisco Hugo Hermógenes de Alencar, Celme Torres Ferreira da Costa.

Socio-environmental analysis of guava production in the municipality of Cariús (CE), Brazil

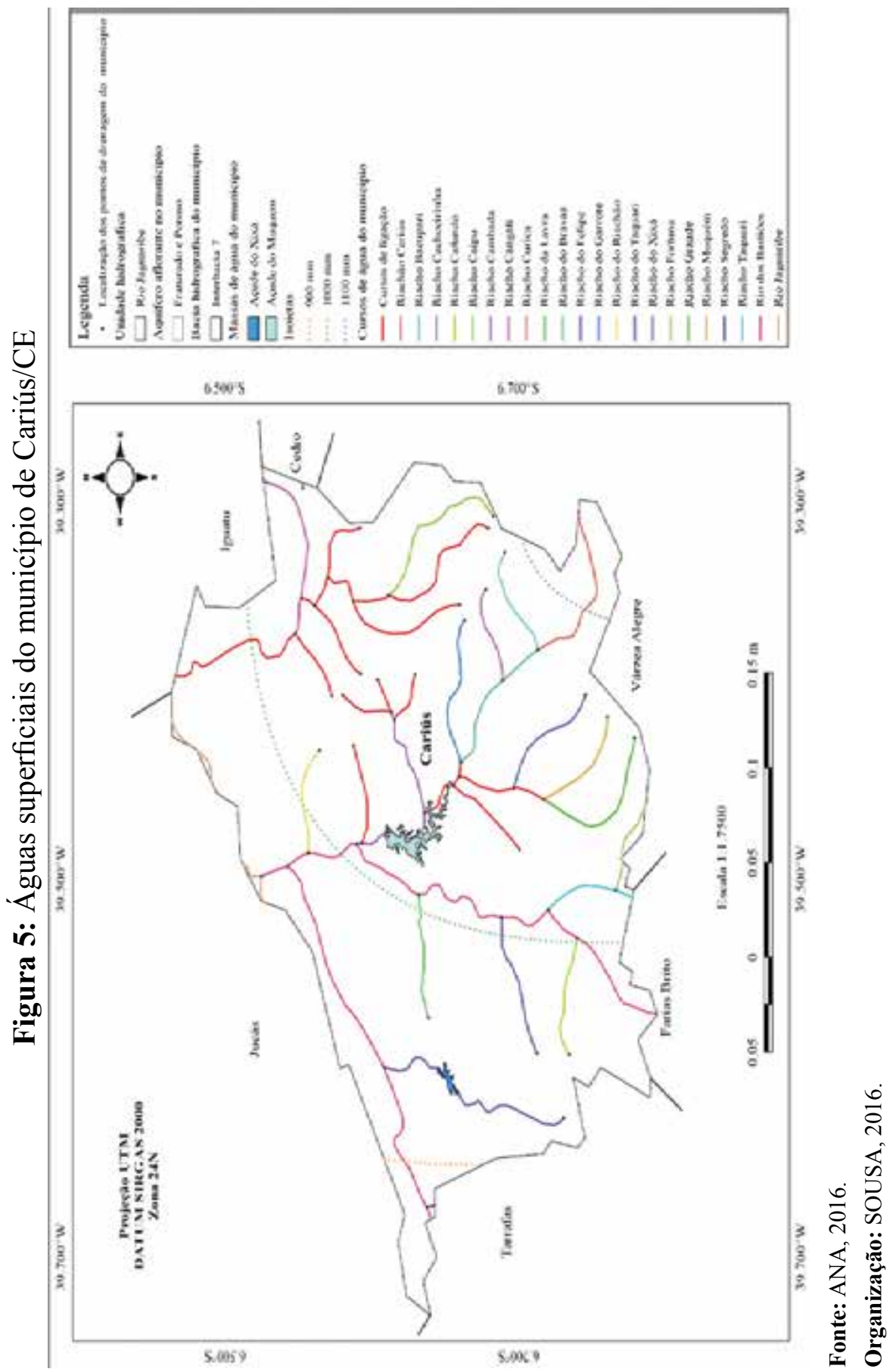




\section{Metodologia}

Entre os messes de outubro de 2015 a janeiro de 2016, foi realizada uma pesquisa junto aos órgãos de extensão (Empresa de Assistência Técnica e Extensão do Ceará - EMATERCE e Instituto Agropolos) e um levantamento das Associações de produtores para localização das propriedades que cultivam goiaba no Município de Cariús - CE (Figura 6).

Figura 6: Localização das propriedades pesquisadas

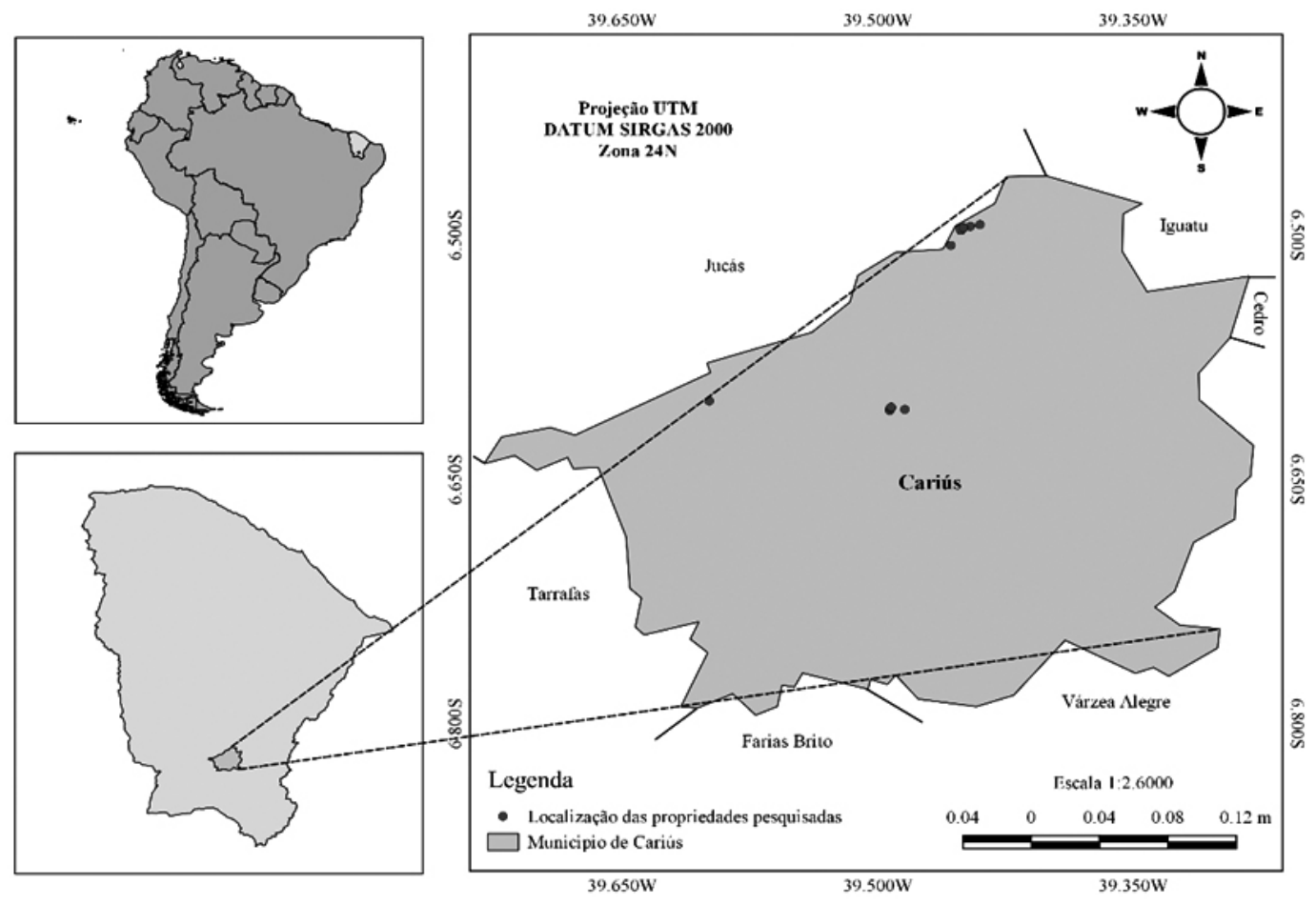

Base de dados: IBGE, 2016.

Fonte: Pesquisa de campo, 2016.

Posteriormente foram levantados junto ao Instituto de Pesquisa e Estratégia Econômica do Ceará - IPECE, Instituto Brasileiro de Geografia e Estatística - IBGE, entre outros, dados relativos à população rural e a produção de goiaba do município. Após estes estudos preliminares, foram feitas expedições aos locais identificados sendo possível o levantamento dos aspectos relevantes, identificados através de registro fotográfico. 
Posteriormente foram realizadas entrevistas semiestruturadas com os agentes envolvidos baseado em Alencar (2006). Nesta oportunidade, todas as propriedades foram georreferenciadas para a elaboração de mapas.

As entrevistas semiestruturadas abordaram aspectos como: características das propriedades, perfil socioeconômico dos trabalhadores e produtores, mercados consumidores das goiabas produzidas no município, saúde, segurança e bem estar dos trabalhadores, gestão ambiental desenvolvida nas propriedades e levantamento dos agrotóxicos utilizados nas propriedades.

A análise dos dados foi feita mediante a organização dos dados coletados em quadros e tabelas de maneira a tornar possível a obtenção das informações para a análise socioambiental dos produtores de goiaba do Município de Cariús. Após o levantamento dos agrotóxicos, foi realizado consultas junto ao Agrofit para verificação das recomendações técnicas e dosagens na cultura da goiabeira.

Baseado nestas informações foi possível conhecer os problemas socioambientais causados pelo cultivo da goiabeira no município de Cariús $-\mathrm{CE}$, Brasil.

\section{Resultados e discussões}

O polo de produção de goiaba de Cariús possui quatorze propriedades: seis no Sitio Canabrava, uma no Sitio Santo André, uma no distrito de São Sebastião e seis no Sitio Agrovila. Ocupa vinte e quatro trabalhadores, dos quais quatorze são proprietários.

Os produtores do Sítio Agrovila estão organizados em uma única Associação: Instituição Sócio comunitária da Agrovila do Açude Muquém de Cariús - ISCA. Todos os associados têm área de produção comum, e produzem em áreas independentes, mas reúnem-se periodicamente para traçar metas para o setor. Os demais produtores são independentes, ou seja, não participam de nenhuma associação.

A diária dos trabalhadores das propriedades é $\mathrm{R} \$ 40,00$ reais diários, cada trabalhador é responsável por 1ha de goiabeira. Entretanto, há propriedades sem trabalhadores e o proprietário é responsável pelo manejo da cultura.

O setor não dispõe de grandes avanços tecnológicos e as propriedades são bastante homogêneas, todas dispõem de uma relativa estrutura 
física e tecnológica (irrigação com microaspersão, motores, caixas de água e boa encanação).

Na região não existe posto de recebimento de embalagens vazias de agrotóxicos e tudo que os produtores necessitam é oferecido pelo comércio local, vale ressaltar que os principais insumos comprados são agrotóxicos e fertilizantes químicos.

Os dados coletados mostraram que todos os proprietários e todos trabalhadores do setor são do sexo masculino. Em relação ao nível de escolaridade dos agentes envolvidos, o maior nível de escolaridade dos produtores é o ensino médio completo com apenas $21,4 \%$, porém a maioria $(57,1 \%)$ tem Ensino Fundamental incompleto. Já os trabalhadores apresentam indicies de escolaridades baixos, apenas $20 \%$ concluíram o ensino fundamental (Figura 7).

Figura 7: Nível de escolaridade dos produtores (A) e trabalhadores (B)

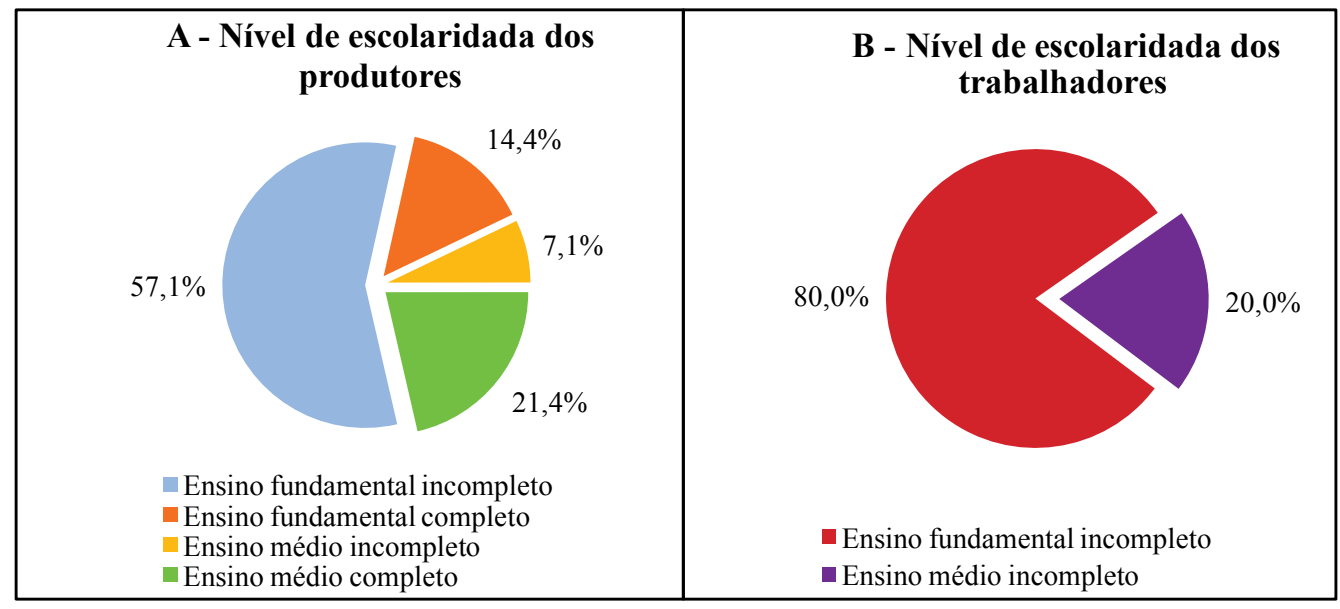

Fonte: Pesquisa de campo, 2016.

A técnica utilizada para o cultivo na região é o campo aberto. Em $50 \%$ das propriedades, utiliza-se água de poço profundo (semiartesiano) que utiliza bomba para retirar água para a irrigação das culturas (Figura 8) e em nenhuma delas há hidrômetro ou outro tipo de controle eficiente no uso da água. Vale salientar que nas propriedades que utilizam água poço profundo é mantido um controle mínimo do uso desse recurso, irrigando mais no período da noite, devido os custos com energia elétrica para a captação da água. 
Figura 8: Fonte de água para irrigação

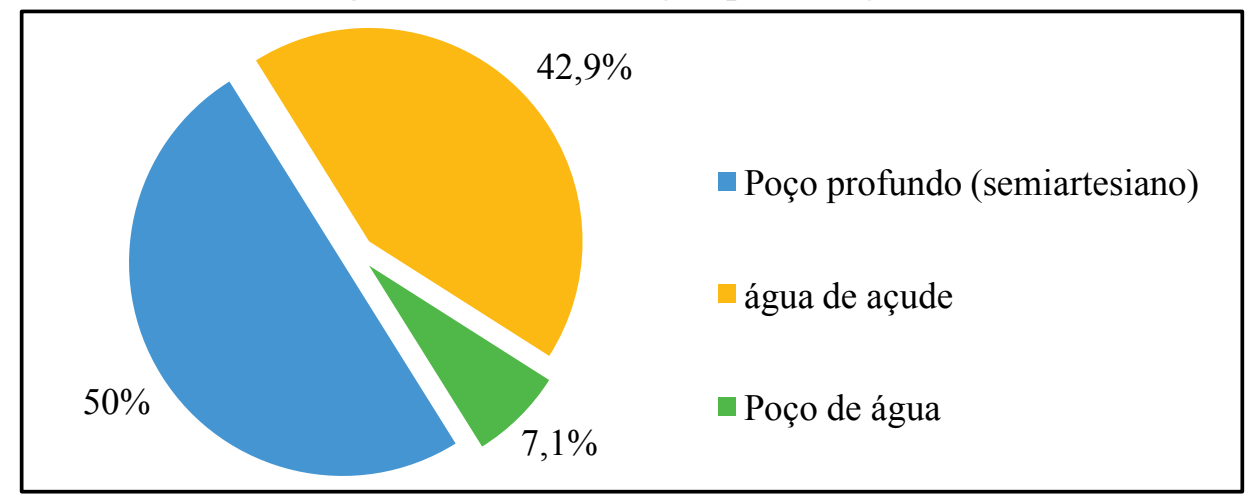

Fonte: Pesquisa de campo, 2016.

A tecnologia utilizada para a irrigação em todas as propriedades analisadas é a microaspersão. As propriedades tem um gasto médio diário estimado em 1.688.400 1/ha em 6 horas de irrigação, que corresponde a $280 \mathrm{~m}^{3} / \mathrm{h}$, que ocorre sempre no período noturno devido ao baixo custo da tarifa de energia elétrica, onde o custo mensal varia de $\mathrm{R} \$ 1.400,00$ a $1.500,00$.

Quanto ao material vegetativo (mudas), a maioria é produzida pelos próprios produtores e parte deste material é adquirida nos municípios cearenses como Lavras da mangabeira, Jaguaribe e Paraíba (Figura 9). 
Figura 09: Localização dos fornecedores de mudas de goiaba

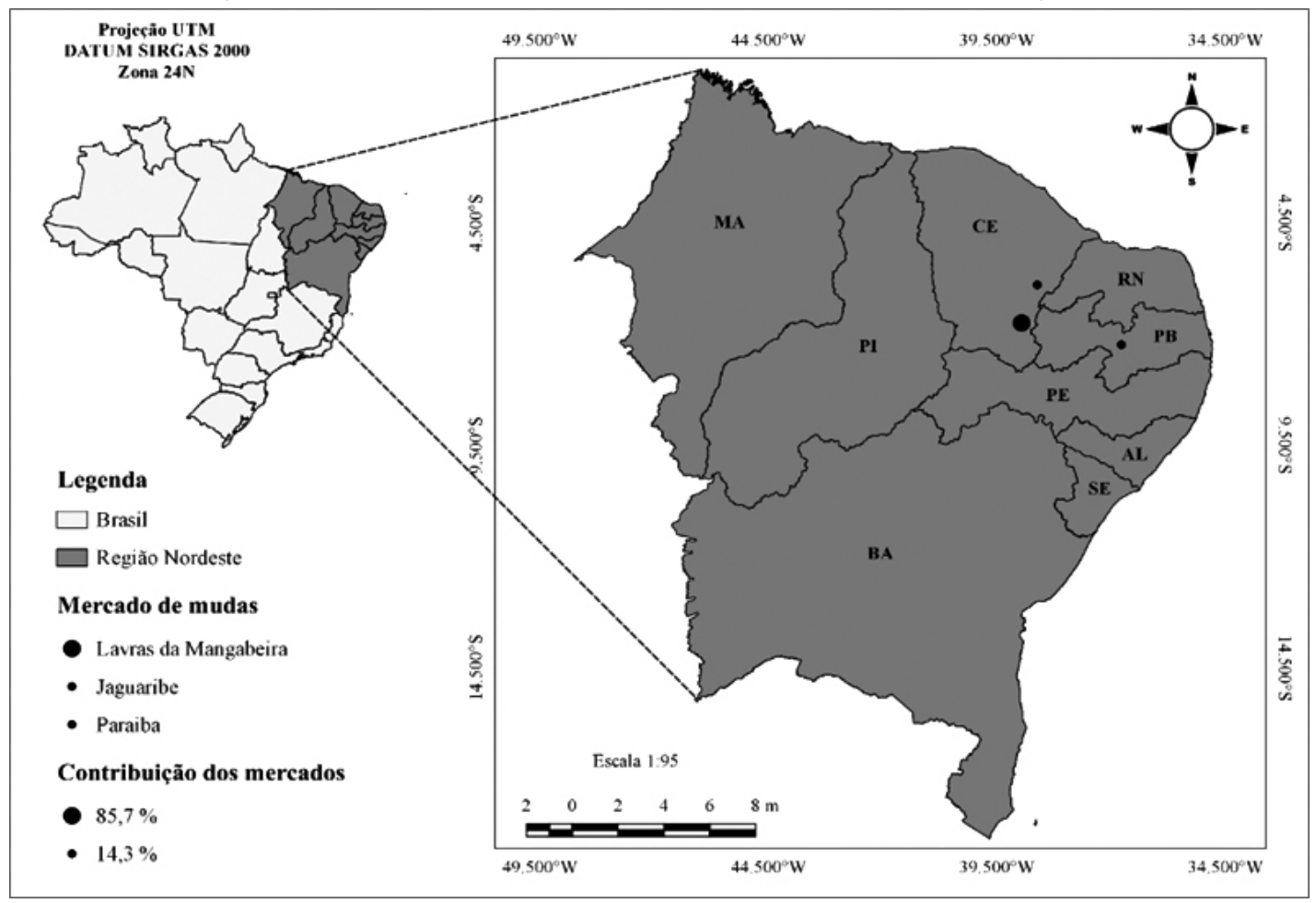

Fonte: Pesquisa de campo, 2016.

Os principais mercados consumidores dos produtos da fruticultura do município de Cariús/CE, são os municípios de Iguatu, Cariús, Crato, Juazeiro do Norte e Barbalha. São abastecidas também outras regiões estados circunvizinhos como Paraíba e Rio Grande do Norte (Figura 10). 
Figura 10: Localização dos principais mercados consumidores de goiaba

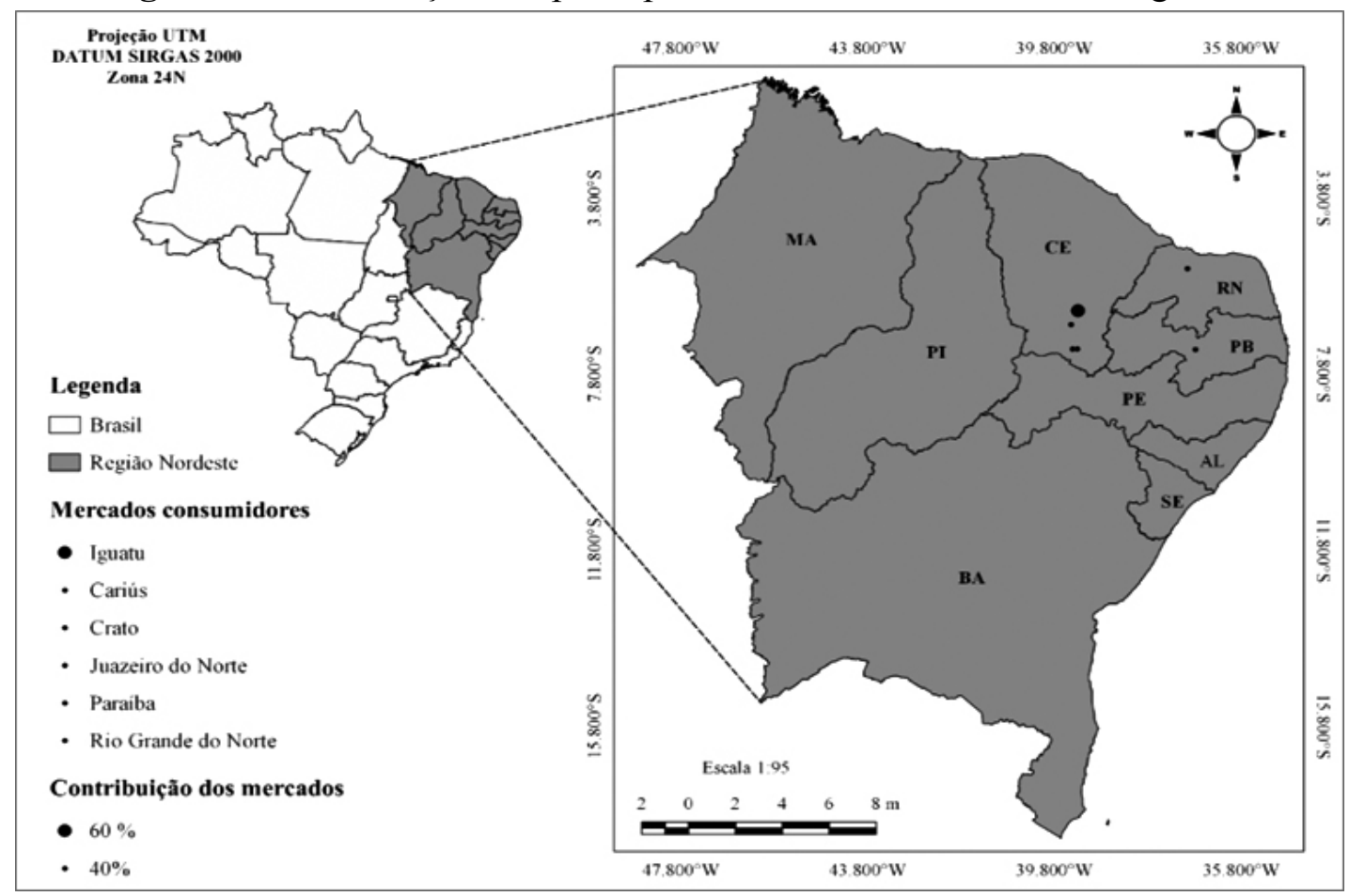

Base de dados: IBGE, 2016

Fonte: Pesquisa de campo, 2016.

A maioria dos trabalhadores $(78,6 \%)$ não utiliza os equipamentos de segurança indispensáveis para o trabalho diário (luvas, máscaras e botas). Nenhuma propriedade dispõe de caixas de primeiros socorros acessíveis. Em caso de acidente, não existe pessoas com treinamento de primeiros socorros.

Nenhuma das propriedades possui sanitários e pias para higienização dos trabalhadores. Em relação aos equipamentos de proteção individual (EPI's) necessários ao manuseio e aplicação de agrotóxicos, treze propriedades têm equipamentos disponíveis, entretanto, os trabalhadores não os utilizam alegando o "desconforto pelo calor". A pulverização é feita com o Aplicador Costal

Apesar da maioria dos aplicadores de agrotóxicos não usarem EPI's, em apenas quatro propriedades os trabalhadores alegaram já ter sentido dores de cabeça, tonturas, mal estar, irritação nos olhos e sensação de queimação 
na pele durante e após a atividade. Em dez propriedades, os aplicadores de agrotóxicos reconheceram que nunca leram a bula de um produto.

Em dez propriedades, os aplicadores de agrotóxicos reconheceram que nunca leram a bula de um produto. Quanto às dosagens de agrotóxicos, na maioria das propriedades $(85,7 \%)$ é feita pelo vendedor, lendo a bula dos produtos e em apenas $14,3 \%$ dos casos é feita pelo proprietário (Figura 11).

Figura 11: Responsáveis pela recomendação das dosagens de agrotóxicos.

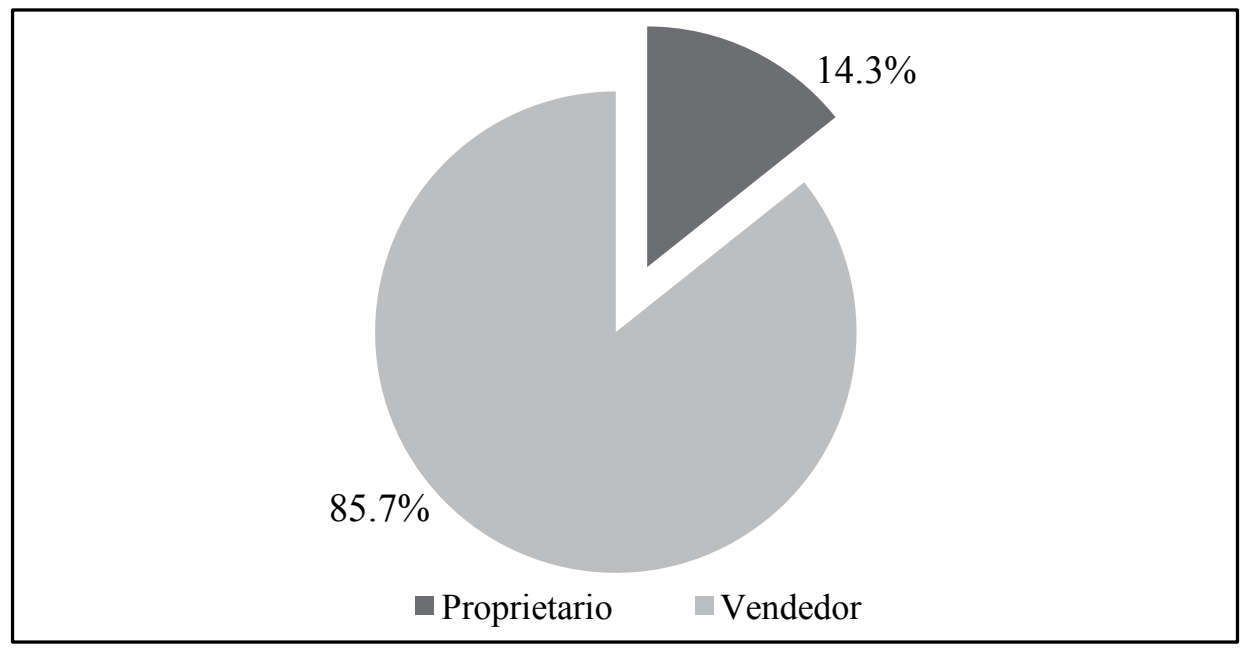

Fonte: Pesquisa de campo, 2016.

O transporte desses produtos geralmente é feito em carro com caçamba, junto com outros produtos, inclusive junto com alimentos e pessoas. Quanto ao armazenamento, todos os agrotóxicos são mantidos nas embalagens originais, porém, o local não é sinalizado e nem apresenta estrutura segura, conforme determina a NBR 9.843 de abril de 2004.

Em nenhuma propriedade há inventário disponível e atualizado dos produtos existentes e não são colocados avisos nos locais de aplicação, para evitar a circulação de pessoas. Os trabalhadores e produtores não realizam e nem conhecem a tríplice lavagem das embalagens vazias e o destino delas quase sempre é o armazenamento em sacos e/ou a incineração, ao invés de serem entregues nas unidades de recebimento, mesmo porque em Cariús e nenhuma cidade próxima dispõe deste serviço. 
A maioria dos produtores aplicam agrotóxicos nas propriedades com frequência quinzenal $(78,6 \%)$ e os demais aplicam mensalmente $(14,3 \%)$. Constatou-se que os mesmos não recebem nenhum tipo de treinamento e não respeitam o período de carência. Outro agravante é que a grande maioria $42,8 \%$ faz a colheita das frutas antes do período de carência dos venenos utilizados, expondo trabalhadores e consumidores à contaminação direta, uma vez que o fruto é frequentemente consumido in natura e com casca.

A produção anual total de todas as propriedades pesquisadas é de $415.000 \mathrm{~kg}$ de goiaba em 13,4 ha, aproximadamente 41,5 toneladas e um rendimento médio de $\mathrm{R} \$ 482.400,00$. Os dados de produção separados das 14 propriedades podem ser observados no Apêndice C.

Quanto à utilização dos agrotóxicos, as 14 propriedades usam 10 tipos diferentes de veneno, mas apenas uma utiliza o produto indicado para a cultura da goiaba, conforme a recomendação do Sistema de Agrotóxicos Fitossanitários - AGROFIT do Ministério da Agricultura, Pecuária e Abastecimento - MAPA. As demais propriedades utilizam agrotóxicos recomendados para outras culturas, conforme demonstrado no Quadro Quadro 2. 
Sostenes Gomes de Sousa, Girlaine Souza da Silva Alencar, Francisco Hugo Hermógenes de Alencar Celme Torres Ferreira da Costa. Análise socioambiental da produção de goiaba do município de Cariús (CE), Brasil

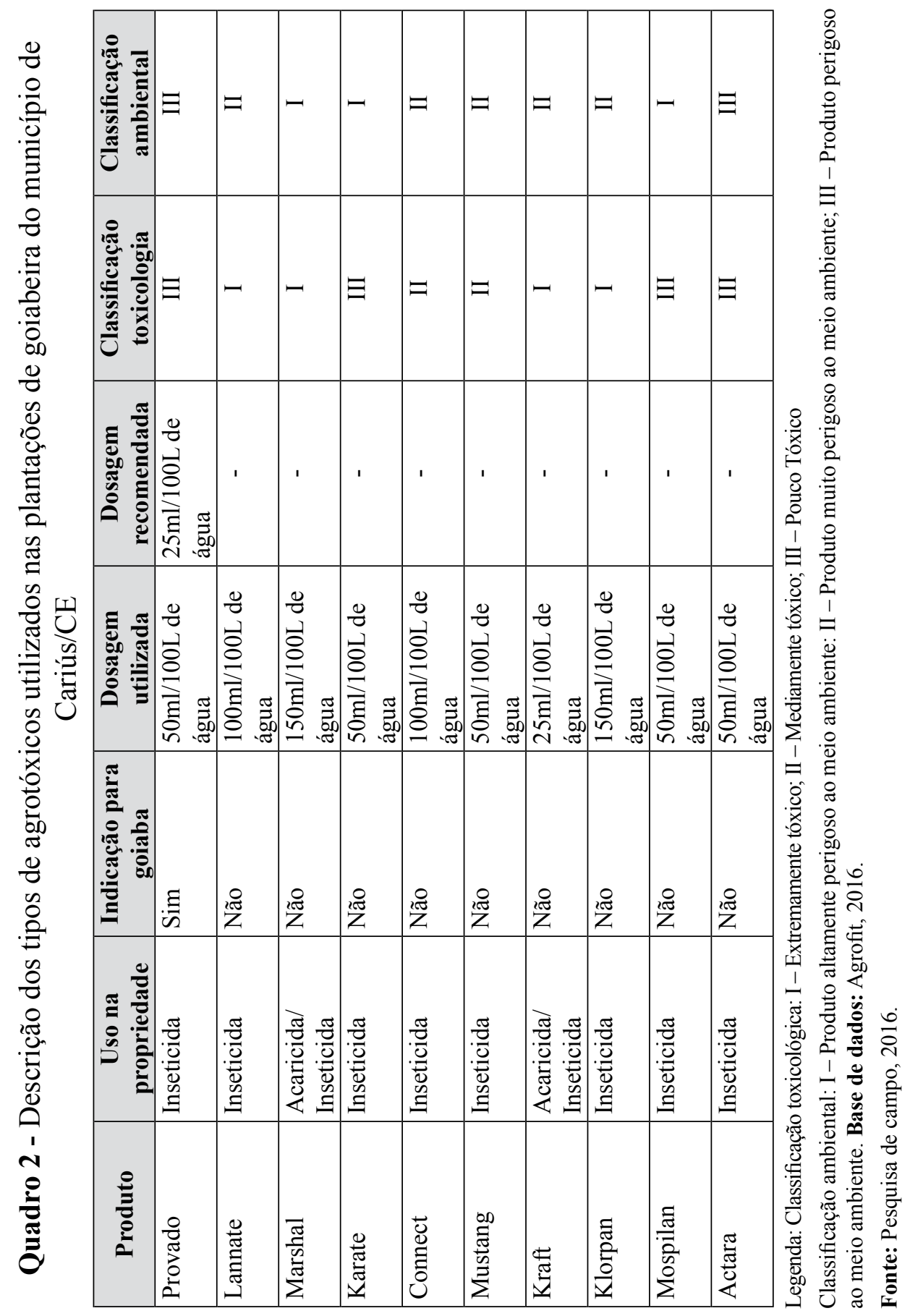


Ao analisar os danos à saúde provocados pelos agrotóxicos segundo dados do AGROFITE (2016), em sua maioria, afetam diretamente o sistema nervoso central. Os principais sintomas clínicos apresentados são: náusea, vômitos, diarreia, debilidade, enjoo e alguns casos irritação nos olhos e na pele. No sistema nervoso central têm-se os efeitos agudos como tremores, ataxia e midríase. Na ocorrência de casos mais graves há relatos de coma, aspiração com insuficiência respiratória, hipotensão, falha múltipla de órgãos e morte.

Em quatro propriedades visitadas os trabalhadores alegaram já ter sentido dores de cabeça, tonturas, mal-estar, irritação nos olhos e sensação de queimação na pele durante e/ou após a atividade.

Outro ponto importante encontrado refere-se ao uso de agrotóxicos não indicados para a cultura da goiaba que ficou evidenciado em 13 propriedades. A utilização inadequada, traz graves consequências para a produção do fruto como má-formação e contaminação das goiabas, resistências das pragas encontradas na lavoura e gastos excessivos com outros agrotóxicos.

\section{Considerações finais}

Identificou-se vários problemas ligados à saúde e segurança dos trabalhadores das plantações como: falta de treinamento para os trabalhadores desempenharem as atividades ligadas ao uso e manuseio de agrotóxicos com conhecimento e segurança, desconhecimento dos procedimentos necessários em caso de emergência, falta de material para prestação de primeiros socorros, ausência de pessoal treinado para assistência ao trabalhador acidentado, não utilização dos equipamentos de proteção individual (EPI) e o transporte inadequado de agrotóxicos.

Identificaram-se vários problemas ligados à saúde e segurança dos trabalhadores das plantações como: falta de treinamento para os trabalhadores desempenharem as atividades ligadas ao uso e manuseio de agrotóxicos com conhecimento e segurança, desconhecimento dos procedimentos necessários em caso de emergência, falta de material para prestação de primeiros socorros, ausência de pessoal treinado para assistência ao trabalhador acidentado, não utilização dos equipamentos de proteção individual (EPI) e o transporte inadequado de agrotóxicos.

Constatou-se que os produtores e trabalhadores tem pouco conhecimento sobre os perigos que os agrotóxicos podem causar a sua saúde dos 
consumidores. $\mathrm{O}$ uso abusivo destes produtos ligados ao gasto excessivo de água nas propriedades poderá levar a contaminação ambiental, dos trabalhadores e área circunvizinha.

Vale ressaltar que a contaminação causada pelo uso de agrotóxicos sem respeito ao período de carência, traz riscos que afetam a saúde e bem-estar dos trabalhadores e principalmente dos consumidores de goiabas, pois os resíduos dos defensivos agrícolas por meio do processo de bioacumulação ficam retidos na superfície da fruta

Entretanto, pontos negativos também foram evidenciados como: o uso indevido dos agrotóxicos seja em relação a sua dosagem (alta), indicação para o uso e falta de treinamento para os aplicadores. O armazenamento incorreto de agrotóxicos e falta de unidades de recebimento de embalagens vazias certamente ocasionará a contaminação ambiental.

Neste contexto, a fruticultura irrigada da goiabeira se configura como uma prática de grande importância socioeconômica para a geração de emprego e renda para o produtor rural do município de Cariús/CE, Brasil. Porém, ela pode gerar impactos socioambientais relevantes como contaminação do solo, da água, do ar e afetar a saúde dos trabalhadores, desta forma, são necessárias medidas urgentes para minimizar os impactos gerados.

Dentre as recomendações para trabalhos futuros, sugere-se que esta metodologia seja aplicada em outras regiões produtoras de frutos para identificação dos impactos socioambientais gerados e conscientização dos agentes envolvidos.

\section{Referências}

Agência de Desenvolvimento do Estado do Ceará (Adece). (2013). Perfil da produção de frutas Brasil Ceará 2013. Fortaleza, (Pp. 1-31). Recuperado: http://www.adece.ce.gov.br/phoca download/Agronegocio/perfil_da_producao_de_fru tas_br asil_ceara_2013_frutal.pdf. Sistema de Agrotóxicos Fitossanitários (Agrofit). Informações do registro de agrotóxicos e afins. Recuperado: http://agrofit.agricultura.gov.br/ agrofit_cons/prin cipal_agrofit_cons.

Albiero, Daniel. et al. (2015). Tecnologias agroecológicas para o Semiárido. Fortaleza: Edição do Autor. (Pp 216). Recuperado: http://www. ppgea.ufc.br/images/diversos/Tecnoloem: giasAgroecologicas.pdf. 
Aldo, C. R. (1997). Água na região Nordeste: desperdício e escassez. Revista Scielo. Disponível em: <http://www.scielo.br/pdf/ea/v11n29/ v11n29a07>. Acesso em: 05 jul. 2015.

Alencar, G. S. S. (2006). A produção de flores e o certificado EUREPGAP: o caso do Agropolo Cariri - Ceará. Dissertação de mestrado. Universidade Federal da Paraíba. João Pessoa. Brasil. (Pp 153).

Alencar, G.S.S. (2013). Código de conduta: uma potencialidade para o desenvolvimento sustentável da floricultura do Agropolo Cariri/CE. Tese de doutorado. Universidade Estadual Paulista. Rio Claro - SP. (Pp 161).

Agência Nacional de Vigilância Sanitária (ANIVA). (2016). Resíduos de agrotóxicos em alimentos. Informe Técnico. Revista Saúde Pública, Brasília, v.40, n.2 (Pp 361-363). Recuperado: <http://www.scielo .br/pdf/rsp/v40n2/28547.pdf $>$.

Araújo, F. V. (2010). Intoxicação por agrotóxico em trabalhadores rurais: uma revisão Bibliográfica. Monografia de especialização em Enfermagem. Universidade Estadual do Ceará. Fortaleza, (Pp 67).

Associação Brasileira De Normas Técnicas. (2004). NBR 9843: agrotóxicos e afins: armazenamento, movimentação e gerenciamento em armazéns, depósitos e laboratórios. Rio de Janeiro. Brasil. Recuperado: http://www.ecoagencia.com.br/docum.entos/norma_agrotoxicos_afins.pdf.

Assunção, L. M.; Livingstone, I. (1993). Desenvolvimento inadequado: construção de açudes e secas no sertão do Nordeste. Revista Brasileira de Economia, v. 47, n. 3. (Pp. 2-24). Recuperado: http://bibliotecadigital.fgv.br/ojs/index.php/rb e/artic le/ view / 582/7932.

Boccolini, P. M. M. (2010). Exposição a agrotóxicos, atividade agrícola e mortalidade por linfoma do tipo não-Hodgkin no Brasil. Dissertação de mestrado. Fundação Oswaldo Cruz. Rio de Janeiro. Brasil. (Pp 70). Recuperado: http ://www.saudepublica.ufc.br/ima gens/u ploads/dissertacoes/172def51d4ce042df50c8bfd178f2ba6.pdf.

Carson, R. (2010). Primavera Silenciosa. 1. ed. São Paulo: Gaia. (Pp 328). Choudhury, M.M., Araújo, J.L.P., Gonzaga Neto, L., Resende, J.M., Costa, T.S., Scaggiante, G. (2001). Goiaba: Pós-colheita. Brasília: Embrapa Informação Tecnológica. (Pp 45). 
Empresa Brasileira de Pesquisa Agropecuária (EMBRAPA). (2006). Centro Nacional de Pesquisa de Solos. Sistema brasileiro de classificação de solos. Rio de Janeiro, Brasil

Freitas, George Alberto de. (2010). Produção e área colhida de goiaba no Nordeste. Bando do Nordeste. INFORME RURAL ETENE, $\mathrm{n}^{\circ} 24$. Recuperado: http://w ww.bnb.gov.br/documents/88765/89729/ire ano4_n24.pdf/76fb9166-aed9-4813-8137-e6d d8b2b37b6.

Fundação Cearense De Meteorologia E Recursos Hídricos (FUNCEME). Dados dos postos pluviométricos do estado do Ceará. Recuperado: $<$ http:// www.fun ceme.br /app/calenda rio/produto/municipios/ maxima/diario?data $=$ hoje.

Geremia, B. (2011). Agrotóxicos: O emprego indiscriminado de produtos químicos no ambiente de trabalho rural e a responsabilização por danos à saúde. Dissertação de estrado. Caxias do Sul. Brasil. (Pp 147). Recuperado: http://tede.ucs.br/tde_busca/ arquivo. php? codArquivo $=471$.

Instituto Brasileiro de Geografia e Estatística (IBGE). Base de dados. Recuperado: http://do wnloads .ibge.gov.br/downloads_estatis ticas. htm.

Instituto Brasileiro de Geografia e Estatística (IBGE). Sistema de recuperação de dados automáticos. Recuperado: http ://www.sidra.ibge. gov.br/bda/agric/default.asp? $\mathrm{t}=4 \& \mathrm{z}=\mathrm{t} \& \mathrm{o}=11 \& \mathrm{u} 1=1 \& \mathrm{u} 2=1 \& \mathrm{u} 3$ $=1 \&$ u $4=19 \&$ u $5=1 \& u 6=1$.

Instituto de Pesquisa e Estratégia Econômica do Ceará (IPECE). Ceará ocupa $1^{\mathrm{a}}$ posição nas exportações de frutas no Brasil. IPECE informe $n^{\mathrm{o}}$ 11. Recuperado: http:// www.ipece. ce.gov.br/news/ ceara-ocupa-1a-posicao-nas-exportacoesde- frutas.

Instituto de Pesquisa e Estratégia Econômica do Ceará. (IPECE). Perfil básico municipal de Cariús 2015. Recuperado: http://www.ipece. ce.gov. br/publicacoes/perfil_basico/pbm-2015/Carius.pdf>.

Molion, L.C.B.; Bernardo, S.O. Dinâmica das chuvas no Nordeste brasileiro. Recuperado: http://www.cbmet.com/cbm-files/12-7ea5f627d14a9f9a88cc694cf707236f.pdf.

Pedroza, E. H. O. (2013). O uso indiscriminado de agrotóxicos e a violação dos direitos fundamentais à alimentação saudável, à saúde e ao meio ambiente equilibrado e suas consequências ao cofre da seguridade 
social. Justiça do direito. v. 27, n. 1. (Pp 220-233). Recuperado: www.u pf.br/seer/index.php/rjd/article/ download/4566/3135.

Peres, F.; Moreira, J. C. (2003). É veneno ou é remédio? agrotóxicos, saúde e ambiente. Rio de Janeiro: Editora FIOCRUZ. (Pp 384). Recuperado: http:/ /static.scielo.org/scielobooks/ sg3mt/pdf/peres-9788575413173.pdf.

Reetz. E. R. et al. Anuário brasileiro da Fruticultura 2014. Santa Cruz do Sul, ed. Gazeta Santa Cruz. (Pp 104). Recuperado: http://www. grupogaz.com.br/editora/anuarios/show/4718. html.

Santos, H.G.; Zaroni, M.J.; Solos trociscais. Recuperado: http://www. agencia.cnptia.embrapa.br/gestor/solos_tropicais/arvore/CONTAG01_16_2212200611542.html.

SEBRAE. O cultivo e o mercado da goiaba. Recuperado: < http:// www. sebrae.Combr/sites /PortalSebrae/artigos/o-cultivo-e-o-mercadoda-goiaba,d3aa9e665b182410VgnVCM10000 0b272010aRCRD. 